\title{
Alterations in Surface Glycoproteins and Level of Sialyltransferase Activity of Human Embryo Kidney Cells Infected with Oncogenic Adenovirus Type 12
}

\author{
Yoshitaka Aoi and Masanori Yokota \\ The Institute of Medical Science, the University of Tokyo, \\ Tokyo 108
}

Aor, Y. and Yокота, M. Alterations in Surface Glycoproteins and Level of Sialyltransferase Activity of Human Embryo Kidney Cells Infected with Oncogenic Adenovirus Type 12. Tohoku J. exp. Med., 1978, 125 (2), 177-183- Human embryo kidney (HEK) cells infected with adenovirus type 12 and its cytocidal mutants $(C y t)$ synthesized different glycoproteins respectively on the cell surface at the early stage of infection. Furthermore, a less and a highly tumorigenic $C y t$ mutants synthesized different glycoproteins. The level of sialyltransferase activity in the microsomes of HEK cells was increased when cells were infected with adenovirus type 12. It was confirmed that there was a positive correlation between the sialyltransferase activity in the microsomes and tumorigenicity. - oncogenic adenovirus type 12; microsomal sialyltransferase activity; tumorigenicity

It is generally accepted that cell surface alterations are the primary biochemical events leading to the loss of growth regulation in virus transformed cells (Tooze 1973). However, what surface alterations are directly related to the development of tumor in vivo still remains to be clarified.

Several approaches have been adopted to find a correlation between the cell surface changes and tumorigenicity (Glick et al. 1973; Glick et al. 1974; Onodera et al. 1976). One of the most important problems may be to isolate the tumor specific transplantation antigen (TSTA) and to elucidate its chemical structure.

Human adenovirus type 12 (H12) is highly oncogenic in hamsters. However, most H12 Cyt mutants are less tumorigenic in hamsters and less efficient in transformation of cells (Takemori et al. 1968; Takemori et al. 1969). These mutants, which do not show the typical cytopathic effect in adenovirus-infected cells, were named on the basis of their cytocydal effect.

The comparison of less tumorigenic H12 Cyt mutants with highly tumorigenic H12 wild type (WT) showed that they differed only in their capacity to induce cell surface changes, such as lectin-agglutinability (Yamamoto et al. 1972; Salzberg and Raskas 1972) and TSTA (Yamamoto et al. 1972). This close correlation between tumorigenicity and the capacity to induce cell surface changes

Received for publication, November 1, 1977. 
provides an efficient system which is useful for analysis of the relationship between transformation and membrane alteration.

In the previous paper (Aoi 1977), the author suggested that the level of sialic acid content in the plasma membrane may be under the control of the microsomal sialyltransferase activity. There may be a link between sialic acid content in the plasma membrane and the transformed phenotype in the cell lines.

This paper describes a comparative study of glycoproteins in the plasma membrane and the sialyltransferase activity in the microsomes of H12WT-infected and Cyt mutant-infected cells. The results also suggest a close correlation between tumorigenicity and alteration in the glycoproteins of the plasma membrane.

\section{Materials and Methods}

Secondary cultures of human embryo kidney (HEK) cells and H12WT, $C y t 31$ and $C y t 66$ mutants were used. These mutants were named by $\mathrm{N}$. Takemori according to the proposal made by Ginsberg et al. (1973). Most $C y t$ mutants are less tumorigenic in hamsters with an exception of $C y t$ 66, which is highly tumorigenic (Takemori et al. 1968) and not defective in inducing cell surface change (Yamamoto et al. 1972). The procedures for cell culture, virus production and virus assay were described previously (Yamamoto et al. 1972).

The plasma membrane and microsomes were prepared according to a modified method of Ray (Ray 1970). The membrane isolation procedure is summarized in Fig. 1. Protein determination was carried out by the method of Lowry (Lowry et al. 1951), using bovine serum albumin as a standard. The activity of sialyltransferase in the microsomes was measured according to a modified method of Grimes (Grimes 1970). Successful application of this method to the microsomes used in this experiment was reported previously (Aoi 1978).

Cells were plated on $65 \mathrm{~mm}$ Falcon Petri dishes at a concentration of $4 \times 10^{5} \mathrm{cells} / \mathrm{dish}$ and grown in Eagle's minimum essential medium (MEM) supplemented with $10 \%$ calf serum. When the cells formed a monolayer, the medium was discarded and the cells were infected with $\mathrm{Hl2WT}, C y t 66$ and Cyt $3 \mathrm{l}$ at $10 \mathrm{PFU} /$ cell, respectively. Fifteen $\mathrm{hr}$ after infection (before the onset of viral DNA synthesis), the cells were labeled with 2.5 $\mu \mathrm{Ci} / \mathrm{ml}$ of ${ }^{3} \mathrm{H}$-glucosamine $\left(\mathrm{D}-6-\left[{ }^{3} \mathrm{H}\right]\right.$-glucosamine, specific activity $25 \mu \mathrm{Ci} / \mathrm{mmol}$, the Radiochemical Centre) for four hr. After being pulse labeled with radioactive sugar as described above, the cells were harvested with rubber policeman (without the use of trypsin) and then centrifuged at $200 \times \mathrm{g}$ for $10 \mathrm{~min}$.

Sodium dodecylsulfate polyacrylamide gel electrophoresis (SDS-PAGE) was carried out by the method of Fairbanks (Fairbanks et al. 1971). Polyacrylamide gels $(7.5 \%$ ) were run with a constant current of $5 \mathrm{~mA} /$ gel until cytochrome c migrated to the bottom of the gel. The following proteins were used as markers for the molecular weight estimation of sample peaks: human globulin $\mathrm{H}$ chain $(\mathrm{I} 60,000)(\mathrm{I})$, bovine serum albumin $(68,000)$ (II), chymotrypsinogen $(25,500)$ (III) and cytochromec $(11,700)$ (IV). They were indicated as (I), (II), (III) and (IV) in the figure. The gels were cut with a gel slicer which gave slices approximately $1.0 \mathrm{~mm}$ width. The slices were swollen overnight at $55^{\circ}$ with $0.3 \mathrm{ml}$ of $\mathrm{H}_{2} \mathrm{O}_{2}$. To each vial were added $10 \mathrm{ml}$ of dioxane scintillation fluid and the radioactivity in each sample was counted by Beckman (SL-200) liquid scintillation counter.

\section{Results}

The isolation procedure of the plasma membrane according to the method of Ray (Ray 1970) except that the following steps were reformed to improve the yield: after centrifugation at $5,000 \times \mathrm{g}$ for $10 \mathrm{~min}$, the precipitates were taken up 


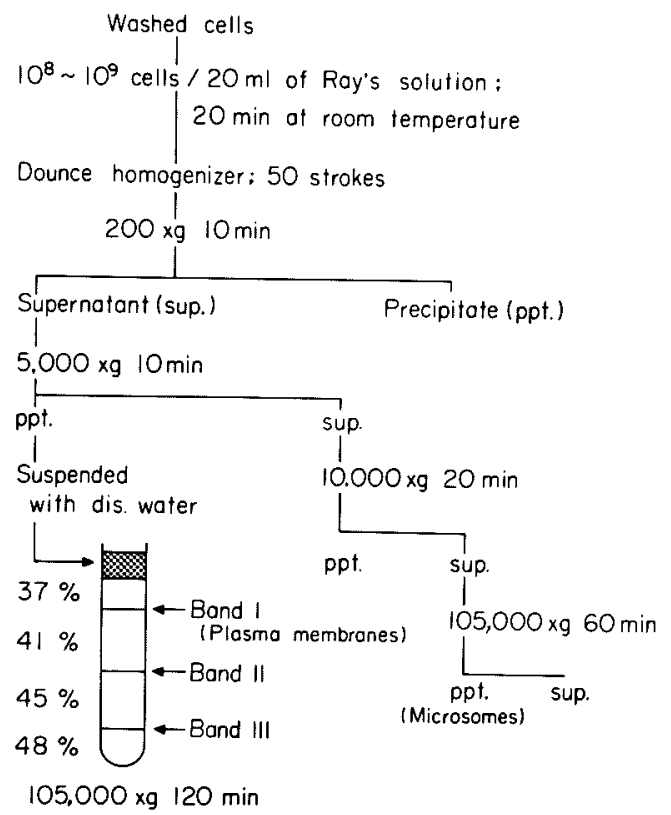

Fig. 1. Isolation procedure of the plasma membrane.

in a small volume of distilled water (1-2 ml), and then this suspension was layered on the $37 \%$ sucrose solution $(w / w)$.

SDS-PAGE patterns of glycoproteins in the plasma membrane newly synthesized by HEK cells are shown in Fig. 2(a). Major components were observed in fraction No. 10 and in fractions Nos. 18-19. Cells infected with H12WT newly synthesized fraction No. 10 glycoprotein, but there was no glycoprotein peak at fractions Nos. 18-19 (Fig. 2(b)). On the other hand, cells infected with either Cyt 31 or Cyt 66 produced a different pattern from that of mock infected or WTinfected cells. The major peak (fraction No. 10) was not detected in either case (Fig. 2 (c), (d)).

The newly synthesized glycoproteins in the virus infected HEK cells were different in the SDS-PAGE patterns. The microsomal sialyltransferase activity involved in the elongation of the terminal carbohydrate (sialic acid) of glycoproteins in the plasma membrane was examined. Cells infected with H12WT and Cyt mutants were harvested at $19 \mathrm{hr}$ after infection and microsomes were prepared. The transfer of CMP- $\left[{ }^{14} \mathrm{C}\right]$-sialic acid to desialized fetuin was measured (Table 1). The activity of sialyltransferase increased by $230 \%$ in WT-infected HEK cells than that of uninfected cells. The level of sialyltransferase in Cyt 66 (highly tumorigenic) infected cells was 1.23 times higher than that of Cyt 31 (less tumorigenic) infected cells. 


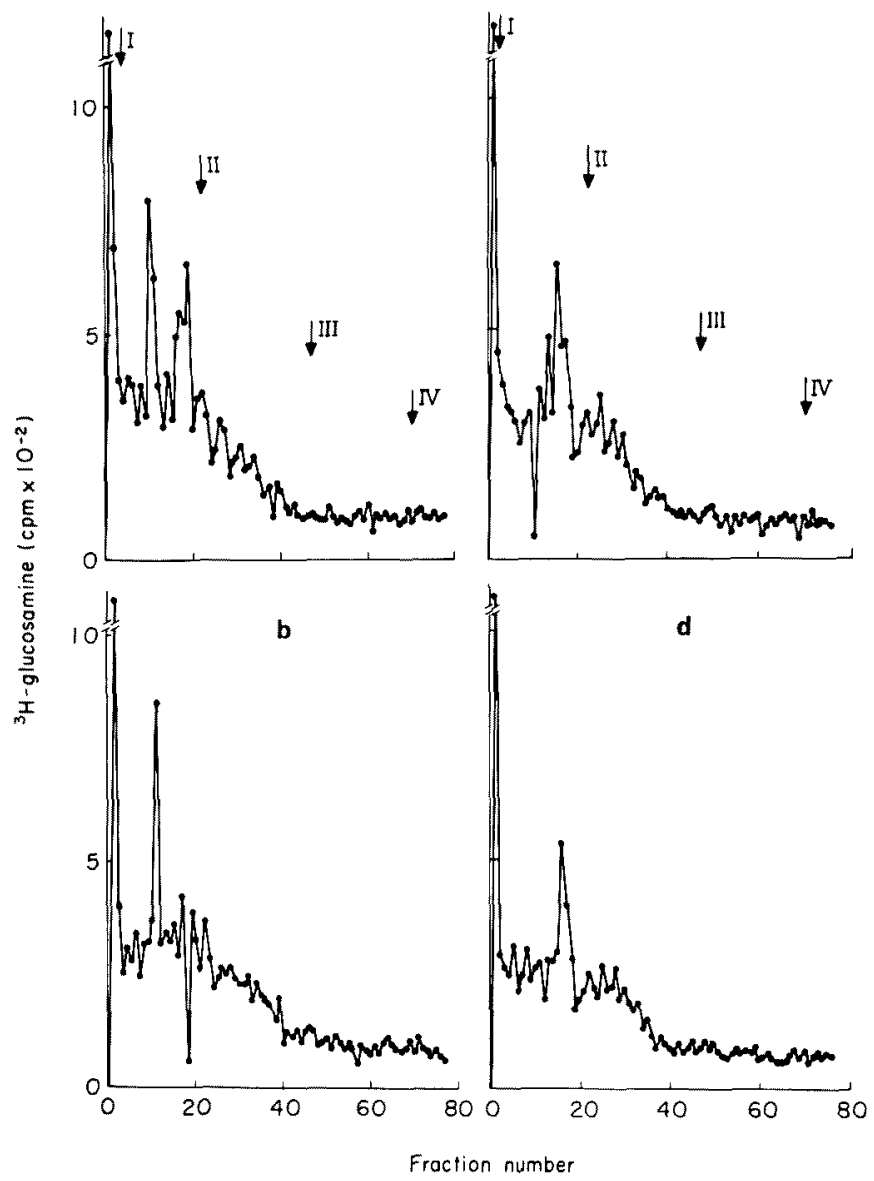

Fig. 2. SDS-PAGE patterns of ${ }^{3} \mathrm{H}$-glucosamine labeled glycoproteins in the plasma membrane.
(a) mock-infected cells.
(b) H12WT-infected cells.
(c) Cyt 31-infected cells.
(d) $C y t$ 66-infected cells.

\section{Discussion}

Concerning the molecular defects of Cyt 31 (less tumorigenic) mutant, two interesting facts have been reported (Yamamoto et al. 1972). First, cells infected with H12WT or Cyt 66 (highly tumorigenic) demonstrated marked lectin agglutinability at $24 \mathrm{hr}$ to $32 \mathrm{hr}$ after infection. In contrast, cells infected with Cyt 31 mutant showed much less marked lectin agglutinability during the infection process. This observation, indicating that Cyt 31 mutant does not induce surface alterations, is in contrast to the marked surface changes induced by H12WT or Cyt 66. Secondly, Cyt 31 does not induce transplantation immunity in hamsters. However, the correlation between the surface alterations induced by infection in vitro and the lack of induction of TSTA in vivo still remains to be clarified. 
TABLE 1. Level of sialyltransferase activity in the microsomal fraction after infection of human adenovirus 12 and Cyt mutants

\begin{tabular}{lc} 
& Sialyltransferase activity \\
\hline Mock infection & $5920 \pm 350^{*}$ \\
H12WT (oncogenic) & $13777 \pm 794$ \\
Cyt 66 (oncogenic) & $10890 \pm 830$ \\
Cyt 31 (less oncogenic) & $8870 \pm 521$ \\
\hline
\end{tabular}

* Results are expressed as the mean \pm s.E. of 3 to 5 determinations, and as cpm/mg of microsomal protein.

The study in this paper was performed to find out biochemical mechanisms for the phenomena described above. It was found that the newly synthesized glycoproteins and the level of sialyltransferase activity in the microsomes were characteristic to the cells infected with each mutant. It is worthy of note that the level of sialyltransferase activity was raised by oncogenic virus infection and that the degree of activation was different depending on the infected mutants. These results seemed to indicate that the level of sialyltransferase activity in the microsomes is related with the tumorigenicity.

Sialic acid content in the plasma membrane has been reported to correspond well with the microsomal sialyltransferase activity (Aoi 1978). Sialic acid in the cell surface glycoproteins has been reported to be involved in the determination of MN antigenicity (Springer and Ansell 1958) and tumor antigen (Sanford 1967; Currie and Bagshawe 1968; Simons et al. 1971; Bekesi et al. 1971). Moreover, the presence or absence of sialic acid on the surface has a considerable effect on the fluidity of the plasma membrane, e.g., Con A agglutinability (Novogradsky and Katchalski 1973; Vaheri et al. 1972; Kemp 1968). In this context, it is considered that sialic acid content in the plasma membrane of HEK cells seemed to be raised by infection of those viruses and altered surface glycoproteins.

On the other hand, it has been known that adenovirus types 1,2 and 5, although classified as non-oncogenic, do transform rodent cells in vitro (Freeman et al. 1967; McAllister et al. 1969; Williams and Ustacebeli 1971) and transformed rat cells are non-tumorigenic (Freeman et al. 1967) unless the animals are immunosuppressed (Gallimore 1972). Whether cells transformed by non-oncogenic adenovirus are related to the level of sialyltransferase activity in the microsomes, is not explored at this moment. Research along this problem is now in progress.

\section{Acknowledgment}

We would like to express thanks to Prof. H. Shimojo of this Institute for his encouragement and the supply of experimental materials.

\section{References}

1) Aoi, Y. (1978) Biosynthesis of glycoprotein-glycosyl transferases during the cell cycle. Tohoku J. exp. Med., 124, 139-144.

2) Aoi, Y. (1978) Sialic acid content and growth control of mouse cells transformed 
by a temperature-sensitive mutant of SV40. FEBS letters, in press.

3) Bekesi, J.G., St-Arneault, G. \& Holland, J.F. (1971) Increase in leukemia L 1210 immunogenicity by vibrio cholerae neuraminidase treatment. Cancer Res, 31, 21302132.

4) Currie, G.A. \& Bagshawe, K.D. (1968) The effect of neuraminidase on the immunogenicity of the Landuschutz ascites tumor; Site and mode of action. Brit. $J$. Cancer, 22, 588-594.

5) Fairbanks, G., Steck, T.L. \& Wallach, D.H.F. (1971) Electrophoretic analysis of the major polypeptides of the human erythrocyte membranes. Biochemistry, 10, 2606-2617.

6) Freeman, A.E., Black, B.H., Vanderpool, E.A., Henry, P.H., Austin, J.R. \& Huebner, R.J. (1967) Transformation of primary rat embyro cells by adenovirus type 2. Proc. nat. Acad. Sci. (Wash.), 58, 1205-1212.

7) Gallimore, P.H. (1972) Tumor production in immunosuppressed rats with cells transformed in vitro by adenovirus type 2. J. gen. Virol., 16, 99-102.

8) Ginsberg, H.S., Williams, J.F., Doerfler, W.H. \& Shimojo, H. (1973) Proposed nomenclature for mutants of adenoviruses. J. Virol., 12, 663-664.

9) Glick, M.C., Rabinovitz, Z., \& Sachs, L. (1974) Surface membrane glycopeptides which coincide with virus transformation and tumorigenesis. J. Virol., 13, 967974.

10) Glick, M.C., Rabinovitz, Z. \& Sachs, L. (1973) Surface membrane glycopeptides correlated with tumorigenesis. Biochemistry, 12, 4864-4869.

11) Grimes, G.W. (1970) Sialic acid transferases and sialic acid levels in normal and transformed cells. Biochemistry, 9, 5083-5092.

12) Johnston, I.R., McGuire, E.J., Jourdian, G.W. \& Roseman, S. (1966) Incorporation of N-acetyl-D-glucosamine into glycoproteins. J. biol. Chem., 241, 5735-5737.

13) Kemp, R.B. (1968) Effect of the removal of cell surface sialic acid on cell aggregation in vitro. Nature, 218, 1255-1256.

14) Lowry, O.H., Rosebrough, N.J., Farr, A.L. \& Randall, R.J. (1951) Protein measurement with the folin phenol reagent. J. biol. Chem., 193, 265-275.

15) McAllister, R.M., Nicolson, M.D., Lewise, A.M., Jr., MacPherson, I. \& Huebner, R.J. (1969) Transformation of rat embyro cells by adenovirus type 1. J. gen. Viol., 4, 29-36.

16) Novogrodsky, A. \& Katchalski, E. (1973) Transformation of neuraminidase treated lymphocytes by soybean agglutinin. Proc. nat. Acad. Sci. (Wash.) 70, 2515- 2518.

17) Onodera, K., Yamaguchi, N., Kuchino, T. \& Aoi, Y. (1976) Alterations in surface glycoproteins and level of sialyltransferase of cells transformed by a temperaturesensitive mutant of simian virus 40. Proc. nat. Acad. Sci. (Wash.) 73, 4090-4094.

18) Ray, T.K. (1970) A modified method for the isolation of the plasma membrane from rat liver. Biochim. biophys. Acta (Amst.), 196, 1-9.

19) Salzberg, S. Raskas, J. (1972) Surface changes of human cells productively infected with human adenoviruses. Virology, 48, 631-637.

20) Sanford, E.H. (1967) An alteration in tumor histocompatibility antigen induced by neuraminidase. Transplantation, 5, 1273-1279.

21) Springer, G.F. \& Ansell, N.J, (1958) Inactivation of human erythrocyte agglutinogen $\mathrm{M}$ and $\mathrm{N}$ by influenza virus and receptor destroying enzyme. Proc. nat. Acad. Sci. (Wash.) 44, 182-189.

22) Takemori, N., Riggs, J.L. \& Aldrich, C.D. (1968) Genetic studies with tumorigenic adenovirus. 1. Isolation of cytocydal $(c y t)$ mutants of adenovirus type 12 . Virology, 36, 575-586.

23) Takemori, N., Riggs, J.L. \& Aldrich, C.D. (1969) Genetic studies with tumorigenic adenovirus. II. Heterogeneity of cyt mutants of adenovirus type 12 . Virology,
$38,8-15$.

24) Tooze, J. (1973) The Molecular Biology of Tumor Viruses. edited by J. Tooze, Cold Spring Harbor Laboratory, New York. 
25) Vaheri, A., Rouslahti, E. \& Nordling, S. (1972) Neuraminidase stimulates division and sugar uptake in density inhibited cell cultures. Nature New Biol., 238, 211-212.

26) Williams, G.F., \& Ustacelebi, S. (1971) Complementation and recombination with temperature sensitive mutants of adenovirus type $5 . J$. gen. Virol, 13, 345348 .

27) Yamamoto, H., Shimojo, H. \& Hamada, C. (1972) Less tumorigenic (cyt) mutants of adenovirus 12 defective in induction of cell surface change. Virology, 50, 743-752. 